\title{
Predictors of dropout from maternal continuum of care in Ethiopia: evidence from the 2016 population- based health survey
}

Minyahil Tadesse Boltena ( $\nabla$ minyahil.tadesse@ahri.gov.et )

Armauer Hansen Research Institute https://orcid.org/0000-0002-5081-1480

\section{Afrah Mohamedsanni}

Addis Ababa University School of Public Health

\section{Benedict Oppong Asamoah}

Lunds Universitet

\section{Lire Lemma}

Wachemo University

\section{Meklit Tesfaye Gebre}

Jimma University College of Public Health and Medical Sciences

\section{Ziad Khatib}

Bibliotheque Cegep de l'Abitibi-Temiscamingue et Universite du Quebec en Abitibi-Temiscamingue

\section{Kababa Temesgen}

Ambo University College of Medicine and Public Health

\section{Abraham Sahlemichael Kebede}

University of Brighton Faculty of Health and Social Sciences

\section{Research article}

Keywords: Continuum of care, Dropout, maternal health, EDHS, Multilevel analysis, Ethiopia

Posted Date: June 9th, 2020

DOI: https://doi.org/10.21203/rs.3.rs-32013/v1

License: (c) (1) This work is licensed under a Creative Commons Attribution 4.0 International License. Read Full License 


\section{Abstract}

Introduction

Integrated primary health care service provided by skilled birth attendants is linked to safe childbirth and postnatal care, vitally improves maternal, newborn, and child health outcomes. Despite a significant reduction in maternal and neonatal mortality in Ethiopia, low maternal service utilization, and dropout from the maternal continuum of care continues to be a major challenge. Therefore, this study aimed to investigate the individual and community predictors of dropout from the maternal continuum of care in Ethiopia.

\section{Methods}

We used data from the 2016 Ethiopian demographic and health survey (EDHS). Women who had a birth in the 5 years preceding the survey were included. Dropout from the maternal continuum of care was the outcome of this study. This includes, attending less than four antenatal care visits (<4 ANC), a dropout from skilled birth attendance (SBA) after having 4 or more ANC, and dropout from postnatal care (PNC) after having SBA. Multilevel logistic regression analysis was employed. The mixed effect and variation in the outcome were expressed by the intracluster correlation coefficient (ICC).

Results

Higher dropouts from SBA to PNC (85\%) and from $\geq 4$ ANC to SBA (43.4\%) in the maternal continuum of care were observed. Women from the poorest wealth quantile ( $A O R=2.31,95 \% \mathrm{Cl} 1.69,3.16)$, not covered by health insurance $(A O R=1.44,95 \% \mathrm{Cl}, 1.01,2.06)$, and residing in a community with high poverty $(A O R=1.28,95 \% \mathrm{Cl}, 1.01,1.63)$ were more likely to attend inadequate ANC. On the other side, distance from a health facility $(A O R=1.45,95 \% \mathrm{Cl}, 1.12,1.88)$, lower community media exposure $(A O R=1.6,95 \% \mathrm{Cl}, 1.14,2.23)$ and rural residency $(\mathrm{AOR}=3.03,95 \% \mathrm{Cl}, 1.75,5.26)$ were associated with dropout from SBA after attending ANC visits. Living in Somali, Harari, and Dire Dawa significantly associated with drop out from the PNC after SBA.

Conclusion

The pattern of dropout from the maternal continuum of care was higher in Ethiopia. Maternal education, wealth index, community media exposure, and distance from a health facility were the factors associated with dropouts from the maternal continuum of care. Home care strategies and contextual understanding of the barriers to the PNC service is needed.

\section{Introduction}

Improving maternal health to ensure their active involvement in the economic and social activities to narrow the observed gap in the millennium development goals (MDGs) in the global south is a prime focus of the sustainable development goals (SDGs)[1]. To accelerate the achievement of the SDG 3.1, which is aimed to reduce the global maternal mortality ratio to less than 70 per 100,000 live births by 2030 , considerable 
emphasis on the experience from the millennium development goals (MDGs) era is deemed important, in which the world has witnessed remarkable progress in the reduction of maternal and newborn deaths (44\% and 47\%) respectively [2-4]. However, the World Health Organization's 2018 fact sheet revealed that every day, 830 women die from pregnancy or childbirth - related complications globally [4].

As a major contributor to the global burden of maternal and neonatal morbidity and mortality, African countries have developed strategies linked to SDGs to help them achieve the set targets [5]. Improving access to quality clinical interventions (modern contraception, a continuum of maternal care, and safe abortion service delivery) were among the priorities [6-8]. Continuum of maternal, newborn, and child health care $(\mathrm{MNCH})$ involves the continuity of care provided to women from preconception, during pregnancy, intrato post-partum in a comprehensive and integrated fashion. This is one of the keys and proven interventions to reduce the yearly toll of half a million maternal, 4 million neonatal, and 6 million child deaths [6, 9-11].

Integrated service where pregnant women obtain access to antenatal care associated with safe childbirth care provided by skilled birth attendants and postnatal care are important [6]. Each component of the continuum of care gives a window of opportunity; ANC allows regular checkups to assess pregnancy and childbirth - related risks, to screen and treat conditions that might threaten the health outcome of both the mother and the baby [12]. Besides, it provides a ground to intervene in nutritional deficiencies (Iron deficiency anemia, Vitamin A, and lodine deficiency) which are common in the global south among women when they begin their pregnancy [13].

Dropout from the continuum of maternal health services is one of the inefficiencies in the healthcare system due to the cost generated by failure to attend health care (underutilization of equipment and personnel) and delayed diagnosis and treatment, which might have contributed to the higher maternal morbidity and mortality [14-16].

Over the last years, Ethiopia has successfully revitalized its national health policy intending to address universal health access by improving the lack of human resources in health $(\mathrm{HRH})$ and infrastructure [1719]. In 2003, the country launched an innovative health extension program (HEP) which trained and deployed over 38,000 health workers [20]. Moreover, there were accelerated midwifery training, integrated emergency surgery, and obstetrics (IESO) task shifting [19]. Furthermore, There was an aggressive capital investment to improve coverage of essential services [21]. Despite all these enacted efforts, the MMR (350/100000 live birth) and NMR (38/1000 live births) in Ethiopia remain one of the highest in the sub Saharan Africa (SSA) region [22]. Evidence indicated that this magnitude of maternal and neonatal mortality is attributed to low maternal health service utilization [9]. According to the 2016 EDHS, the use of maternal care services was low, with ANC coverage of $32 \%$, institutional delivery $26 \%$, and PNC service coverage $17 \%$ $[20,22,23]$.

Studies have revealed physical inaccessibility [24], prohibitive costs [12] and sociocultural practices [25, 26] are among the commonly mentioned reasons for the low utilization of maternal services in Ethiopia. In addition, there are disparities in service utilization among regions [27], places of residence (urban, rural) [28], and between different social and economic classes [29-31]. Critically and comprehensively understanding 
the individual and community level contributors to dropout from the maternal continuum of care could help to design a tailored strategy to improve adherence to the maternal continuum of care.

Though the community level variables give better intervention opportunities to policymakers [32], previous studies primarily addressed the role of individual variables with less emphasis put on community - level variables. Therefore, this study aimed to shed light on the comprehensive assessment of the individual and community level predictors for the dropout from the maternal continuum of care in Ethiopia.

\section{Materials And Methods}

\section{Study design and source of data}

The 2016 EDHS, which is the fourth series of the demographic health surveys, a nationally representative survey which collects data on mortality, morbidity, fertility, use of family planning, and maternal and child health was used in this study. The dataset was requested from measure DHS website (www.dhsprogram.com) [22]. The survey used the 2007 population and housing census (PHC) conducted by the central statistical agency (CSA) as a sampling frame to select enumeration areas (EAs). The census provided a complete list of all EAs. The survey employed a stratified two stages sampling technique. The primary sampling unit was composed of regions stratified into urban and rural areas, within 21 sampling strata. In the first stage, 645 EAs (202 in urban areas and 443 in rural areas) were selected proportionally. In the second stage, 28 households per cluster were selected with equal probability systematic selection from the newly created household listing. The survey was implemented by the CSA, Ministry of Health (MOH) and the ICF international. Detailed methodology and sampling methods used to collect the data is available elsewhere [33]. Women aged 15-49 years, either permanent residents of the selected households or visitors who stayed in the households the night before the survey were eligible to be interviewed. The current analysis specifically focused on the dropout from the maternal continuum of care pathway (ANC, delivery, and postnatal care) among women who had their last delivery in the 5 years preceding the survey.

\section{Measurements}

\section{Outcome variable:}

The outcome of this study was a dropout from the maternal continuum of care, which was comprised of the three levels of maternal care.

i. $<4$ ANC attendance: women who did not receive 4 or more focused ANC during their most recent pregnancies were coded " 1 " and for those who attended $\geq 4$ ANC visits were coded " 0 ".

ii. Skilled Birth Attendance (SBA) drop out: women who attended 4 or more ANC but did not attend SBA (delivery was not assisted by health professional i.e. doctor, midwife, health officer, and/or nurse) were coded as " 1 " (and otherwise " 0 ").

iii. Postnatal care (PNC) dropout: mothers who sought skilled birth but did not attend postnatal care within the first 2 months of delivery were coded as " 1 " (otherwise " 0 "). 


\section{Independent variables}

The individual - level variables include: I) maternal age in years, grouped as: below 18, 18-34 and 35 and above; II) mother's education categorized as no formal education, primary, secondary and higher education; III) mother's working status, categorized as currently working or not working; IV) wealth index is a composite measure of household socioeconomic status, which is based on ownership of selected assets and then analyzed using principal component analysis and classified into five wealth quantiles as poorest, poorer, middle, richer and richest.

Other pregnancy and reproductive related explanatory variables were the number of children ever born to a mother categorized as (one, 2-4 and above 5). The desirability of the pregnancy for the recent birth was asked and the response categorized into wanted then, later or not at all. The role of the partner in maternal health care utilization (husband's educational status and occupation status) was also examined. Also, the mother's autonomy to make decisions to seek care was included.

The community - level variables were computed based on the enumeration areas (clusters) used in the 2016 EDHS. Community educational status was categorized into higher and lower community educational level based on the proportion of mother's attendance to secondary and higher education in the community using the median as a cutoff point. Community poverty status was based on the proportions of mothers from the poorest and poorer wealth index in the primary sampling unit, categorized as, higher (proportion above the median value) or lower (below the cut off median value). Community media exposure was based on three variables (frequency of listening radio, watching TV, and reading newspaper), which was categorized based on the proportion of exposure to either of this media. The variables were categorized into higher (the proportion above the median cut off) or lower (below the median) levels of exposure. Place of residence was categorized into either rural or urban. The administrative region in Ethiopia; there are 9 regions and 2 city administrations which were included; this was Tigray, Afar, Amhara, Oromia, Somali, Benishangul, SNNPR, Gambela, Harari, Addis Ababa, and Dire Dawa

\section{Data analysis}

Data extracted from the DHS program were cleaned and coded to better suit the purpose of the current analysis. We used STATA version 14 SE (Stata Corp, College Station, TX) for analysis. Descriptive statistics that explores the magnitude of maternal health care services in Ethiopia based on different factors were analyzed and described using frequency tables and percentages.

We performed multilevel multivariable logistic regression analysis. The model was fitted to examine the fixed effect (a measure of associations) and the random effect (variation component) on the outcome variables; having < 4 ANC visits, a dropout from SBA after having 4 or more ANC visits and postnatal care (PNC) after delivering at health institutions. Given the hierarchical nature of the DHS data using a multilevel analysis was considered as an appropriate method of analysis[34].

A two-level multivariable analysis (mothers nested within clusters) was conducted using four models for each dependent variable. The first model was a null model (Intercept the only model), which shows the log- 
odds of dropping from a maternal health service in the absence of covariates in the model. It provides the variance component of random effect, which helps to determine whether there is significant variability in dropout from the continuum of care, between the communities. The second model, on the other hand, examined the effects of individual - level variables on dropout from maternal health care. The third model examined the effect of community - level variables. The final model, included all the individual (selected socio-economic and demographic variables and pregnancy related) and community - level variables to predict their respective effect on the dropout from the maternal continuum of care. The magnitude of the association was presented using the adjusted odds ratio (AOR) and $95 \%$ confidence interval. The variation in the outcome between the clusters (EAs) was measured by the intracluster correlation coefficient (ICC). We tested the model fit statistics using the log likelihood ratio test.

The random intercept logit model and the parameters used to estimate the association between explanatory variables and outcome variables were presented in the following model:

\section{$\log \left[\frac{\pi \mathrm{ij}}{1-\pi \mathrm{ij}}\right]=\beta \mathrm{o}+\beta_{1} X_{\mathrm{ij}+} \beta_{2} \mathrm{X}_{\mathrm{ij} \ldots} \ldots .+\mathrm{u}_{\mathrm{ij}}[34]$}

where $\pi_{i j}$ is the predicted probability of the outcome variable among dropouts(i) and attended( () and $\beta$ o is the constant log odds that $y=1$ when the covariates and random effect equals zero $(X=0$ and $u=0)$ which shows the overall intercept in the linear relationship between the log-odds and $X$. The $\beta_{1,2,3}$ in the multivariable two-level logistic regression indicates the fixed effects of explanatory variables across all categories and levels $i$ and $j$ (selected sociodemographic variables, socioeconomic, and community level variables). Whereas, $\mathrm{X}_{\mathrm{ijk}}$-is a covariate vector and $\mathrm{u}_{\mathrm{ij}}$-is the intercept residual (error component) and it is assumed to be normally distributed with variance $\sigma^{2}$.

\section{Random effects}

The random effect was expressed in terms of intra-cluster correlation coefficient (ICC) which indicated the proportion of total variance on dropout from the maternal continuum of care attributable to the community

level (clustering) effect. The ICC was computed using the formula $\frac{\sigma_{\sigma_{u 0}^{2}}^{2}}{\sigma_{u+}^{2}+\sigma_{u 1}^{2}}$, where $\sigma_{\mathrm{u} 0}$ : represents the intercept variance and $\sigma_{\mathrm{u} 1}$ is the variance with an independent variable.

\section{Ethics and consent}

The DHS has gone through all the necessary ethical procedures. For this study, the first author requested the dataset and permission were granted to use for this analysis.

\section{Result}

Table 1 shows the coverage of different levels of maternal service utilization and patterns of dropout from the maternal continuum of care. In Ethiopia, 2415 (32\%) women attended 4 or more ANC visits whereas $5160(68 \%)$ of them attended $<4$ or no ANC visits. The majority, $67 \%$ and $92 \%$ had no SBA and PNC during 
their recent pregnancy respectively. Among those who received 4 or more ANC visits, $56 \%$ of them reported they had SBA, whereas $44 \%$ dropped out of the care. Only $15.1 \%$ of the mothers who attended SBA visited PNC and the majority $85 \%$ dropped out from the PNC service.

Table 2 shows the individual - level characteristics of the women included in this study. It included: selected sociodemographic characteristics, economic variables, partner - related variables, distance from health facilities with dropout from different levels of maternal care. The majority of women that dropped out from maternal care had their most recent birth at age 18-34, had no education and reported not currently working. A sizeable proportion, and of mothers were covered by health insurance among those who had $<4$ ANC visits (68\%), dropped out from SBA (44\%), and dropped out from PNC (85\%).

Table 3 presents the community - level characteristics among those who dropped out from the maternal continuum of care. The majority of the women were rural residents. Among those women, $73 \%, 56 \%$, and $87 \%$ of them attended $<4$ ANC visits, dropped out from SBA, and dropped out from PNC service, respectively. Most of the dropouts from maternal care (ANC and SBA) were among communities where community educational level was proportionally lower. While dropout from PNC service was more common among communities with higher community education level. The dropout distribution by regions was also presented. The dropout was higher across the maternal continuum of care in the Oromia region.

\section{Multilevel analysis}

Table 4 presents the random effect of clusters on <4ANC attendance, drop out form SBA and PNC which contributed to the variation at the cluster level. The variation in the likelihood of attending $<4$ ANC visits and dropping out from SBA services among clusters was significant. As the intercept only model indicated, the variability between the community in <4 ANC attendance, drop out from SBA, and PNC services was $44 \%$, $52 \%$, and $19 \%$, respectively.

Table 5 presents the multilevel multivariable logistic regression result of selected individual and community level variables (mother and husband educational status, wealth index, health insurance, owning a bank account, living in different regions, community poverty status and community media exposure) on having $<4$ ANC visits, drop out from SBA and PNC. The odds of having <4 ANC visits were 1.6 times higher among those with no formal education compared to those with higher education (AOR: 1.6, 95\% $\mathrm{Cl} 1.21-2.10$ ). Women from the poorest (AOR: 2.3, 95\% Cl 1.69-3.16), poorer (AOR: 1.52, 95\% Cl 1.12-3.05) and middle (AOR: 1.4, 95\% Cl 1.05-1.89) wealth quantiles were found to have significantly higher odds of having less than 4 ANC visits compared to those from the richest wealth quantiles. The odds of having $<4$ ANC visits were 1.3 times more likely among communities with higher poverty status compared to those with lower poverty status (AOR: $1.3,95 \% \mathrm{Cl} 1.01-1.63$ ). The odds of $<4$ ANC attendance was $50 \%$ higher among women in communities with lower media exposure (AOR: $1.5,95 \% \mathrm{Cl} 1.23-1.86$ ) than women in communities in high media exposure.

Mothers with no formal education were almost two times more likely to dropout from SBA after attending 4 or more ANC visits compared to those who attended higher education (AOR: 1.78, 95\% CI 1.07-2.95). Those mothers whose husbands did not attend formal education and primary education were 1.7 (AOR: 1.7, 95\% Cl 
1.16-2.60) and 1.9 (AOR: $1.9,95 \% \mathrm{Cl} 1.32-2.73$ ) times more likely to drop out from the continuum of maternal care compared to those mothers whose husbands had higher education. The odds of dropout from maternal care were as twice high among mothers from the poorest wealth quantiles as compared to the highest wealth quantiles ( $A O R=1.8,95 \% \mathrm{Cl} 1.02-3.03$ ). Distance from the health facility was positively associated with dropout from SBA. The odds of dropping out from SBA after attending 4 or more ANC visits were 1.4 times higher among mothers who perceived distance from the health facility as a big problem compared to those who did not (AOR: 1.5, 95\% Cl 1.12-1.88). Living in Afar (AOR: 5.6, 95\% Cl 2.01-15.9) and Somali (AOR: 4.2, 95\% Cl 1.53-11.64) regions were associated with dropping out from SBA. Also, lower community media exposure was associated with a higher dropout rate from the SBA (AOR: $1.6,95 \% \mathrm{Cl}$, 1.142.23).

Living in Harari, (AOR: 9.9, 95\% Cl 4.14-23.95), Somali, (AOR: 4.9 95\% Cl 1.93-12.3), Dire Dawa, (AOR: 3.0 $95 \% \mathrm{Cl} 1.55-5.66$ ), and Oromia (AOR: $2.6,95 \% \mathrm{Cl} 1.32-5.04$ ) regions were found to be significantly associated with the dropout rate from postnatal care after SBA.

\section{Discussion}

In this study, we assessed the individual and community level predictors of attending $<4$ ANC visits, drop out from SBA and postnatal care in Ethiopia, using the EDHS 2016. A higher dropout from the continuum of care was observed. In this study we tried to present factors correlated with the dropout from the maternal continuum of care. The multilevel multivariable logistics regression analysis indicated mother's and husband's literacy, wealth index, and distance from a health facility were among the individual - level factors found to significantly predict dropout from one or more than one level of maternal care. Similarly, community - level factors including place of residence, community media exposure, and region of residence showed significant associations with dropouts from different levels of the maternal continuum of care.

As shown in this study, literacy was associated with all levels of dropout from the continuum of care. This finding was in line with studies done in Ethiopia, Ghana, Cambodia, and Nepal respectively [27, 35-37]. The consistency in these findings reinforces the critically important role that literacy plays in the overall health seeking behavior. A study conducted in North Ethiopia documented higher education level is associated with better awareness of danger signs and health care attendance [38]. Evidence has also suggested the possible correlation between women empowerment and improved maternal health care service utilization [39]. Women's education is one of the keys enabling and empowering mechanisms, which gives women the autonomy over the decisions needed to be taken including decisions related to access to and availability of health care services $[40,41]$. Countries and stakeholders should continue and strengthen efforts put into educating adolescent girls and young women, in line with SDG 4, to reduce maternal dropout from health care service and the subsequent adverse outcomes. Apart from this, creating peer learning platforms and positive role models at the community level could be promoted through formal education.

Higher odds of inadequate ANC attendance were observed among women whose husbands hadn't a formal education. This finding reiterates the importance of the husband's role in maternal care services and how the husband's educational status is equally important to reduce the risk of dropout from maternal care 
service. This finding is similar to another study done in Nigeria [42]. Over the past several years male involvement has been championed as one of the strategies to increase healthcare service attendance, family planning uptake, and avoid delays [43].

The household wealth index was found to be an important factor in the dropout from ANC and SBA services. This finding was in agreement with different studies done elsewhere in the developing regions [44, 45]. In Ethiopia, though the $\mathrm{MNCH}$ services are being rendered for free, the economic disparities continue to contribute to the differences observed in the utilization of health care services. This might be attributed to the indirect costs incurred such as transportation (tariffs, road qualities, inaccessibility of cheap transport facilities) and health facilities related costs (physical accessibility, availability of the required health care, and availability of special care need for medical complications). A multi-sectoral collaboration aiming at empowering women in terms of owning financial properties and safety net programs where women can play a productive role and engage in economic activities should be encouraged.

Perceived distance from the health facility was an important factor in dropout from SBA care. Similar studies from Ethiopia and Nigeria documented perceived distance from health facilities as one factor to dropout from the maternal continuum of care $[46,47]$. The physical inaccessibility, either perceived or actual, continues to be an important hindrance to the maternal continuum of care adherence in a healthcare setting like Ethiopia. To reduce this physical barrier, the government has recently employed a new birth preparedness and readiness strategy, called maternity waiting homes, where a mother can stay and receive health care at the health facility compound before birth. Further, a phenomenological understanding of the sociocultural factors on women's preference of home deliveries is needed.

Place of residence continues to be a major source of inequality in maternal health care utilization. This difference signifies the disparity in access to information, health service availability, literacy, and financial ownership, and gender inequality between urban and rural communities. We observed higher odds of dropout from the maternal continuum of care among rural residents. Community outreach programs aimed to improve the awareness, access to information and quality health service availability need to be strengthened with a special focus on the rural community. And also, community media exposure was significantly associated with attending $<4$ ANC visits and dropping out from SBA. This finding underscored the unprecedented role of media in improving the health literacy of the community [30]. Using local communications strategies and working closely with media is important to easily disseminate information, which can address the health seeking - behavior of the community.

There was a significant contribution by some regions to the postnatal care dropout. Sociocultural beliefs surrounding delivering at home, where recently delivered mothers are not allowed to go outside their home to seek medical care might be a possible explanation behind the variations [25]. Understanding the reasons for the higher drop out from postnatal care need to be explored using qualitative research to get a better picture and fully understand the contextual factors. Designing an alternative strategy like home-to-home postnatal checkups by mid-level health professionals and integrating the service with other services like immunization will avert the dropout and improve service utilization. 
Though this study gives a comprehensive assessment of the individual and community level factors contributed to dropout from maternal care, this study has few limitations. The nature of the study design doesn't allow us to establish a temporal relationship implies that caution should be taken when making inferences regarding causal associations. Secondly, there might be a possible recall bias as the event occurred anywhere between the preceding 5 years. Thirdly, the distance to the facility was measured based on the individual's perceptions that does not reflect the actual distance from the health facility. Thus, their perceptions could be confounded by the individual's prevailing contexts, including opportunities or hindrances to travel over different distances.

\section{Conclusion}

Individual - level variables (mother's education level, husband's educational status, wealth index, number of children, perceived distance from health facility), and lower community media exposure were associated with maternal dropouts from different maternal health care points. Tailored strategies should be designed to increase the awareness of mothers toward maternal health care adherence. Variables studied could not provide explanations for possible reasons underlying the dropping out of postnatal care. This necessitates further contextual investigations to understand the barriers of postnatal care utilization after getting delivery care. The Ethiopian Federal Ministry of Health (EFMOH) also needs to consider other means of delivering postnatal care like home-to-home visits by mid-level health professionals to increase the service uptake.

\section{Abbreviations}

AOR

Adjusted Odds Ratio

ANC

Antenatal Care

CSA

Central Statistical Agency

DHS

Demographic and Health Survey

EAs

Enumeration Areas

EDHS

Ethiopian demographic and health survey

EFMOH

Ethiopian Federal Ministry of Health

HEP

Health Extension Program 0

$\mathrm{HRH}$

Human Resources in Health

ICC

Intracluster Correlation Coefficient 
MMR

Maternal Mortality Rate

$\mathrm{MNCH}$

Maternal, Newborn, and Child Health Care

MDGs

Millennium Development Goals

$\mathrm{MOH}$

Ministry of Health

NMR

Neonatal Mortality Rate

PNC

Postnatal Care

$\mathrm{PHC}$

Population and Housing Census

SBA

Skilled Birth Attendance

SDGs

Sustainable Development Goals

\section{Declarations}

\section{Acknowledgement}

The authors would like to thank the DHS program for allowing us to use the data.

\section{Funding}

There is no funding received for this particular study.

\section{Availability of data and materials}

The data set collected and used in this study are available at the official website of the DHS program website (www.dhsprogram.com).

\section{Consent for publication}

Not applicable

\section{Competing interest}

The authors declare that there are no financial and institutional competing interests

\section{Authors contribution}


Conceptualization and data curation: ASK, methodology: BAO, MTB, LL, MTG, ZK; formal analysis: ASK, MTB, LL, BAO, writing original draft: AMS, KTD, ASK, BAO, MTB, ZK. Writing-review and editing: all authors. All authors of this paper contributed from the conception, design of the study, and finalizing the work. ASK produced the draft of the manuscript and other authors reviewed and contributed to the final draft. All authors read and approved the final manuscript.

\section{References}

[1] UN Women. Women and Sustainable Development Goals [Internet]. UN Women. 2016. Available from: https://doi.org/10.1108/eb010586.

[2] UN News Centre. Transforming our world: the 2030 Agenda for sustainable Development. United Nations Department of Economic and Social Affairs [Internet]. 2015; Available from: http://www.un.org/en/development/desa/news/sustainable/un-adopts-new-global-goals.html\#more-15178.

[3] Patton GC, Coff C, Sawyer SM, et al. Global patterns of mortality in young people: a systematic analysis of population health data. :881-892.

[4] World Health Organization. Maternal mortality [Internet]. WHO Fact sheets. 2018. Available from: https://www.who.int/en/news-room/fact-sheets/detail/maternal-mortality.

[5] World Health Organization; Regional Committee for Africa. Health in the 2030 Agenda for sustainable development. 2016.

[6] Kerber KJ, Graft-johnson JE De, Bhutta ZA, et al. Continuum of care for maternal , newborn , and child health: from slogan to service delivery. 2007;370.

[7] Bhutta ZA, K. Srinath Reddy. Achieving Equity in Global Health. 2015;3-4.

[8] Good D for. Improve Maternal and Newborn Health and Nutrition. Facts, Solutions, Case studies and Calls to Action. 2015.

[9] Sines BE, Tinker A, Ruben J. The Maternal-Newborn-Child Health Continuum of Care: A collective effort to save lives. Population reference bureau. 2006;

[10] Say L, Chou D, Gemmill A, et al. Global causes of maternal death: a WHO systematic analysis. 2006;323-333.

[11] Every Woman EC. The global strategy for women's, children's and adolescents' health(2016-2030). 2015;

[12] World Health Organization. Opportunities for Africa's Newborns: Practical data, policy and programmatic support for newborn care in Africa. The Partnership: for maternal, newborn and child health [Internet]. 2006;79-90. Available from: http://www.who.int/pmnch/media/publications/oanfullreport.pdf. 
[13] Lawrie T, Bucagu M, Portela A. WHO recommendations on antenatal care for a positive pregnancy experience - going beyond survival. BJOG. 2017;124:860-862.

[14] Car J, Gurol-Urganci I, De Jongh T, et al. Mobile phone messaging reminders for attendance at scheduled healthcare appointments. Cochrane Database of Systematic Reviews. 2008.

[15] London. England is in a sexual health crisis , MPs say. BMJ. 2001;326:273-273.

[16] McLean S, Booth A, Gee M, et al. Appointment reminder systems are effective but not optimal: results of a systematic review and evidence synthesis employing realist principles. Patient Preference and Adherence [Internet]. 2016;10:479-499. Available from: https://www.dovepress.com/appointment-remindersystems-are-effective-but-not-optimal-results-of--peer-reviewed-article-PPA.

[17] World Health Organization. Ministry of Health Ethiopia, PMNCH, WHO, World Bank, AHPSR and participants in the Ethiopia multistakeholder policy review. Success Factors for Women's and Children's Health. 2015.

[18] Action IFOR. Federal Democratic Republic of Ethiopia Ministry of Health Policy And Practice. 2014;6.

[19] Federal Democratic Republic of Ethiopia Ministry of Health. Health sector development programme IV. 2010.

[20] Services OC, Economic C, Associates P, et al. Background Paper Success Factors for Women 's and Children 's Health: Country Specific Review of Data and Literature on 10 Fast- Track Countries ' Progress Towards MDGs 4 and 5 An input to the country policy analyses and multistakeholder. 2013;

[21] Wang H, Ramana GN V. Universal Health Coverage for Inclusive and Sustainable Development: Lessons from Japan. Universal Health Coverage for Inclusive and Sustainable Development: Lessons from Japan. 2014;

[22] EDHS. Ethiopia Demographic and Health Survey 2016: Key inidcators Report. Addis Ababa; 2016.

[23] Ahmed A. Maternal mortality trend in Ethiopia. (Special Issue: Maternal and newborn health.). Ethiopian Journal of Health Development [Internet]. 2010;24:115-122. 45 ref. Available from: ttp://www.cih.uib.no/journals/EJHD\%5Cnhttp://Ishtmsfx.hosted.exlibrisgroup.com/Ishtm? sid=OVID: caghdb\&id=pmid:\&id=doi:\&issn=10216790\&isbn $=\&$ volume $=24 \&$ issue $=$ Special + Issue $+1 \&$ spage $=115 \&$ pages $=115-$ 122\&date=2010\&title=Ethiopian+Journal+of+Health+Development\&ati.

[24] Gebrehiwot Y, Tewolde BT. International Journal of Gynecology and Obstetrics Improving maternity care in Ethiopia through facility based review of maternal deaths and near misses. International Journal of Gynecology and Obstetrics [Internet]. 2014;127:S29-S34. Available from: http://dx.doi.org/10.1016/j.ijgo.2014.08.003. 
[25] Kea AZ, Tulloch O, Datiko DG, et al. Exploring barriers to the use of formal maternal health services and priority areas for action in Sidama zone, southern Ethiopia. 2018;1-12.

[26] Sumankuuro J, Crockett J, Wang S. Perceived barriers to maternal and newborn health services delivery: a qualitative study of health workers and community members in low and middle-income settings. 2018;

[27] Mekonnen ZA, Lerebo WT, Gebrehiwot TG, et al. Multilevel analysis of individual and community level factors associated with institutional delivery in Ethiopia. BMC Research Notes. 2015;1-9.

[28] Tarekegn SM, Lieberman LS, Giedraitis V. Determinants of maternal health service utilization in Ethiopia: analysis of the 2011 Ethiopian Demographic and Health Survey. 2014;14:1-13.

[29] Fekadu GA, Ambaw F, Kidanie SA. Facility delivery and postnatal care services use among mothers who attended four or more antenatal care visits in Ethiopia : further analysis of the 2016 demographic and health survey. 2019;0-9.

[30] Houston Department of Health and Human Services. Health Equity Report [Internet]. 2012. Available from: https://www.houstontx.gov/health/communitytransformation/HE_Assessmentt_Final.pdf.

[31] Singh A. Supply-side barriers to maternal health care utilization at health sub-centers in India. PeerJ [Internet]. 2016;4:e2675. Available from:

http://www.ncbi.nlm.nih.gov/pubmed/27833824\%5Cnhttp://www.pubmedcentral.nih.gov/articlerender.fcgi? artid=PMC5101621.

[32] Ononokpono DN, Odimegwu CO. Contextual Determinants of Maternal Health Care Service Utilization in Nigeria. 2013;37-41.

[33] Dhs D and HS-M. Demographic and Health Surveys Methodology. 2013.

[34] Hox J. Multilevel Analysis: Techniques and applications. Mahwah, New Jersey: Lawrence erlbaum associates; 2003.

[35] Yeji F, Shibanuma A, Oduro A, et al. Continuum of Care in a Maternal , Newborn and Child Health Program in Ghana: Low Completion Rate and Multiple Obstacle Factors. 2015;1-23.

[36] Wang W, Hong R. Levels and determinants of continuum of care for maternal and newborn health in Cambodia- evidence from a population-based survey. 2015;1-9.

[37] Yebyo H, Alemayehu M, Kahsay A. Why Do Women Deliver at Home? Multilevel Modeling of Ethiopian National Demographic and Health Survey Data. 2015;1-14.

[38] Gedefaw A, Muluken A, Tesfaye S. Factors associated with Institutional delivery service utilization among mothers in Bahir Dar City administration, Amhara region: A community based cross sectional study. Reproductive Health. 2014;1-7. 
[39] Angore BN, Tufa EG, Bisetegen FS. Determinants of postnatal care utilization in urban community among women in Debre Birhan Town, Northern Shewa, Ethiopia. Journal of Health, Population and Nutrition. 2018;1-9.

[40] Adhikari R. Effect of Women 's autonomy on maternal health service utilization in Nepal: a cross sectional study. BMC Women's Health [Internet]. 2016;1-7. Available from: http://dx.doi.org/10.1186/s12905-016-0305-7.

[41] Ghose B, Feng D, Tang S, et al. Women 's decision-making autonomy and utilisation of maternal healthcare services: results from the Bangladesh Demographic and Health Survey. 2017;1-8.

[42] Dahiru T, Oche OM. Determinants of antenatal care, institutional delivery and postnatal care services utilization in Nigeria. Pan African Medical Journal. 2015;21:1-17.

[43] Sahilemichael; A, Temsgen; K, Kejela G. Determinants of Long Acting Reversible Contraceptives Use among Child Bearing Age Women in Dendi District, Western Ethiopia. Women 's Health Care. 2015;4.

[44] Iqbal S, Maqsood S, Zakar R, et al. Continuum of care in maternal , newborn and child health in Pakistan: analysis of trends and determinants from 2006 to 2012. 2017;1-15.

[45] Bhatta DN, Aryal UR. Paternal Factors and Inequity Associated with Access to Maternal Health Care Service Utilization in Nepal: A Community Based Cross-Sectional Study. 2015;1-14.

[46] Fisseha G, Berhane $Y$, Worku A, et al. Distance from health facility and mothers ' perception of quality related to skilled delivery service utilization in northern Ethiopia. 2017;749-756.

[47] Akinyemi JO, Afolabi RF, Awolude OA. Patterns and determinants of dropout from maternity care continuum in Nigeria. BMC Pregnancy and Childbirth [Internet]. 2016;1-11. Available from: http://dx.doi.org/10.1186/s12884-016-1083-9.

\section{Tables}

Table 1 Patterns of dropout from the maternal continuum of care among women (N=7590), Ethiopia Demographic Health Survey 2016. 


\begin{tabular}{|c|c|c|c|}
\hline Variable & Category & Frequency (n) & Percentage $(\%)$ \\
\hline \multirow[t]{2}{*}{ Antenatal care (ANC) } & $\square 4 \mathrm{ANC}$ & 2415 & $32 \%$ \\
\hline & $<4$ ANC & 5161 & $68 \%$ \\
\hline \multirow[t]{2}{*}{ Delivery care } & Attended SBA & 2524 & $33.3 \%$ \\
\hline & Not attended SBA & 5065 & $66.7 \%$ \\
\hline \multirow[t]{2}{*}{ Postnatal care (PNC) } & Had PNC & 632 & $8.3 \%$ \\
\hline & Had no PNC & 6953 & $91.7 \%$ \\
\hline \multirow[t]{2}{*}{ Next level of care after attending $\geq 4$ ANC } & Continued to SBA ( $\square 4$ ANC + SBA) & 1374 & $56.6 \%$ \\
\hline & Dropped out ( 44 ANC -SBA) & 1055 & $43.4 \%$ \\
\hline \multirow[t]{2}{*}{ Next level of care after having SBA } & Continued to PNC (SBA+PNC) & 362 & $15.1 \%$ \\
\hline & Dropped out (SBA-PNC) & 2043 & $84.9 \%$ \\
\hline
\end{tabular}

Table 2 Background characteristics of respondents dropped out from maternal health care services, Ethiopia Demographic and Health Survey, 2016. 


\begin{tabular}{|c|c|c|c|}
\hline Variables & $\begin{array}{l}<4 \text { ANC } \\
\mathrm{n}=5160 \mathrm{n} \\
(\% *)\end{array}$ & $\begin{array}{l}\text { Had } \geq \text { ANC but no delivery care } \mathrm{n}=1055 \mathrm{n} \\
(\% * *)\end{array}$ & $\begin{array}{l}\text { Had delivery care but no PNC within the first } 2 \\
\text { months } \\
\mathrm{n}=2043 \mathrm{n}\left(\%^{* * *}\right)\end{array}$ \\
\hline \multicolumn{4}{|l|}{ Age groups (Years) } \\
\hline Below 18 & $174(2.3)$ & $30(1.3)$ & $77(3.2)$ \\
\hline $18-34$ & $3559(47)$ & $770(31.9)$ & $1567(65.1)$ \\
\hline Above 35 & $1428(18.9)$ & $255(10.5)$ & $399(16.6)$ \\
\hline \multicolumn{4}{|c|}{ Mother Educational status } \\
\hline No Education & $3624(75.8)$ & $664(57.4)$ & $830(86.7)$ \\
\hline Primary & $1319(61.4)$ & $354(42.7)$ & $766(85.9)$ \\
\hline Secondary and above & $218(33.6)$ & $37(8.7)$ & $447(80.4)$ \\
\hline \multicolumn{4}{|c|}{ Husband Educational status } \\
\hline No education & $2668(76.9)$ & $451(58.5)$ & $595(87.6)$ \\
\hline Primary & $1821(66.7)$ & $445(49)$ & $689(84.3)$ \\
\hline Secondary and above & $440(44.6)$ & $79(14.7)$ & $597(83.5)$ \\
\hline \multicolumn{4}{|l|}{ Mother working status } \\
\hline Not working & $3820(70.6)$ & $803(50.6)$ & 1308(86) \\
\hline Working & $1341(61.9)$ & $252(30.5)$ & $735(83.1)$ \\
\hline \multicolumn{4}{|l|}{ Wealth Index } \\
\hline Poorest & $1344(81.5)$ & $200(65.7)$ & $192(89.4)$ \\
\hline Poorer & $1235(74.7)$ & $248(59.3)$ & $349(90.5)$ \\
\hline Middle & 1138(71.8) & $254(56.8)$ & $357(85.5)$ \\
\hline Richer & $909(63.8)$ & $262(50.7)$ & $394(85.6)$ \\
\hline Richest & $534(42.3)$ & $91(12.5)$ & $752(81)$ \\
\hline \multicolumn{4}{|l|}{ Health Insurance } \\
\hline No & $4986(68.7)$ & $1009(44.4)$ & 1921(85) \\
\hline Yes & $175(55)$ & $46(32)$ & $122(82)$ \\
\hline \multicolumn{4}{|l|}{ Child ever born } \\
\hline 1 & $829(57.9)$ & $157(26.1)$ & $656(82.8)$ \\
\hline $2-4$ & 2097(65.9) & $455(41.9)$ & $910(86)$ \\
\hline $5+$ & $2235(78.5)$ & $443(61)$ & $477(86)$ \\
\hline \multicolumn{4}{|l|}{ Pregnancy wanted } \\
\hline Then & $379(75.9)$ & $65(54)$ & $87(85)$ \\
\hline Later & $145(75.6)$ & $31(66.1)$ & $38(94)$ \\
\hline Not at all & $59(76.9)$ & $9(52)$ & 13(86.2) \\
\hline \multicolumn{4}{|c|}{ Own account in a bank or other financial institutions } \\
\hline Yes & $307(37.2)$ & $81(15.6)$ & $447(78.3)$ \\
\hline No & $4854(71.9)$ & $974(51.3)$ & 1596(87) \\
\hline \multicolumn{4}{|l|}{ Mobile Ownership } \\
\hline No & $595(43.3)$ & $912(55.7)$ & $1315(87.5)$ \\
\hline Yes & 4566(73.6) & $143(18.4)$ & 728(80.7) \\
\hline \multicolumn{4}{|c|}{$\begin{array}{l}\text { Perceived distance to health } \\
\text { facility }\end{array}$} \\
\hline Big problem & $3295(43.5)$ & $623(25.8)$ & $870(36.2)$ \\
\hline Not a big problem & $1866(24.6)$ & $432(17.9)$ & $1173(49)$ \\
\hline
\end{tabular}


ANC: Antenatal care, PNC: Postnatal care; SBA: skilled birth attendance $*$ Denominator $=$ those with $<4$ ANC $+\square 4$ ANC visits; $* *$ Denominator $=$ the sum of all those who Had ANC 4 but No SBA and who had ANC and had SBA; ***Denominator = sum of all those who had Had delivery care but no PNC within the first 2 months and those who had SBA and had no PNC.

Table 3 Community characteristics of women dropped out from maternal service care, Ethiopia Demographic and Health Survey, 2016.

\begin{tabular}{|c|c|c|c|}
\hline Variables & $\begin{array}{l}<4 \text { ANC } \\
\mathrm{n}=5161 \mathrm{n} \\
(\% *)\end{array}$ & $\begin{array}{l}\text { Had ANC } 4 \text { but no delivery care } \mathrm{n}=1055 \mathrm{n} \\
\left(\%{ }^{* *}\right)\end{array}$ & $\begin{array}{l}\text { Had delivery care but no PNC within the first } 2 \\
\text { months } \\
n=2043 n(\% * *)\end{array}$ \\
\hline \multicolumn{4}{|c|}{ Place of Residence } \\
\hline Urban & $356(37 \%)$ & $49(8 \%)$ & $662(81.3 \%)$ \\
\hline Rural & $4804(72.7 \%)$ & $1006(55.6 \%)$ & $1381(86.8 \%)$ \\
\hline \multicolumn{4}{|c|}{ Community Education } \\
\hline Low & $3652(48.2)$ & $666(27.6)$ & $783(32.5)$ \\
\hline High & $1508(19.9)$ & $389(16.1)$ & $1260(52.4)$ \\
\hline \multicolumn{4}{|c|}{$\begin{array}{l}\text { Community poverty } \\
\text { status }\end{array}$} \\
\hline Low & $2272(30)$ & $553(22.9)$ & $1356(56.4)$ \\
\hline High & $2888(38.1)$ & $502(20.8)$ & $687(28.6)$ \\
\hline \multicolumn{4}{|c|}{$\begin{array}{l}\text { Community media } \\
\text { exposure }\end{array}$} \\
\hline Low & $2720(35.9)$ & $568(23.5)$ & $687(28.6)$ \\
\hline High & $2440(32.2)$ & $487(20.2)$ & $1356(56.4)$ \\
\hline \multicolumn{4}{|l|}{ Region } \\
\hline Tigray & $228(3)$ & $63(2.6)$ & $273(11.3)$ \\
\hline Afar & $56(0.74)$ & $8(0.32)$ & $11(0.47)$ \\
\hline Amhara & $1116(14.7)$ & $247(10.2)$ & $397(16.5)$ \\
\hline Oromia & $2434(32.1)$ & $374(15.5)$ & 696(28.9) \\
\hline Somali & $236(3.1)$ & $15(0.64)$ & $48(2.1)$ \\
\hline Benishangul & $47(0.62)$ & $15(0.64)$ & 19(0.79) \\
\hline SNNPR & $986(13)$ & $317(13.1)$ & $420(17.4)$ \\
\hline Gambela & $12(0.15)$ & $3(0.12)$ & $9(0.35)$ \\
\hline Harari & $11(0.15)$ & $2(0.06)$ & $10(0.4)$ \\
\hline Addis Ababa & $21(0.29)$ & $6(0.25)$ & $142(5.9)$ \\
\hline Dire Dawa & $11(0.15)$ & $6(0.24)$ & $19(0.78)$ \\
\hline
\end{tabular}

ANC: Antenatal care, PNC: Postnatal care; SBA: skilled birth attendance $*$ Denominator $=$ those with $<4$ ANC $+\square 4$ ANC visits; $* *$ Denominator $=$ the sum of all those who Had ANC 4 but No SBA and who had ANC and had SBA; ***Denominator = sum of all those who had Had delivery care but no PNC within the first 2 months and those who had SBA and had no PNC. 


\begin{tabular}{|l|l|l|l|}
\hline Random effect & $<4$ ANC & Had ANC 4 but no delivery care & Had delivery care but no PNC within the first 2 months \\
\hline & AOR $(95 \%$ CI $)$ & AOR $(95 \%$ CI $)$ & AOR $(95 \%$ CI $)$ \\
\hline Community variation & $2.59(2.17,3.09) *$ & $3.53(2.71,4.61)^{*}$ & $0.79(0.51,1.22)$ \\
\hline ICC $(\%)$ & $44 \%$ & $52 \%$ & $19.4 \%$ \\
\hline Log likelihood & -4085.3 & -1475.5 & -1142.3 \\
\hline
\end{tabular}

Model: null model (intercept only model) Abbreviations: - ICC: Intracluster correlation coefficient, Significance level: $*$ p $<0.05$

Table 5 Multilevel logistic regression analysis of individual and community factors on dropout from the maternal continuum of care among women with a live birth in five years preceding 2016 EDHS, Ethiopia. 


\begin{tabular}{|c|c|c|c|}
\hline \multirow[t]{2}{*}{ Variables } & $<4$ ANC & Had ANC 4 but no delivery care & Had delivery care but no PNC within the first 2 months \\
\hline & AOR $(95 \% \mathrm{CI})$ & AOR $(95 \% \mathrm{CI})$ & AOR $(95 \% \mathrm{CI})$ \\
\hline \multicolumn{4}{|l|}{ Age groups (Years) } \\
\hline Below 18 & ref & ref & ref \\
\hline $18-34$ & $1.2(0.79,1.72)$ & $1.0(0.48,1.98)$ & $1.3(0.63,2.52)$ \\
\hline Above 35 & $1.3(0.86,2.03)$ & $0.9(0.41,1.99)$ & $1.1(0.49,2.39)$ \\
\hline \multicolumn{4}{|l|}{ Educational status } \\
\hline No Education & $1.6(1.21,2.10) *$ & $1.8(1.07,2.95) *$ & $1.3(0.81,2.05)$ \\
\hline Primary & $1.2(0.92,1.51)$ & $1.6(1.02,2.54) *$ & $1.2(0.85,1.74)$ \\
\hline Secondary and above & ref & ref & ref \\
\hline \multicolumn{4}{|c|}{ Husband's educational status } \\
\hline No education & $1.5(1.16,1.82) *$ & $1.7(1.16,2.60) *$ & $0.9(0.61,1.42)$ \\
\hline Primary & $1.1(0.93,1.41)$ & $1.9(1.32,2.73) *$ & $0.8(0.57,1.12)$ \\
\hline Secondary and above & ref & ref & ref \\
\hline \multicolumn{4}{|l|}{ Mother's working status } \\
\hline Not working & $0.98(0.85,1.14)$ & $1.3(1.01,1.71)$ & $1.4(1.09,1.85) *$ \\
\hline Working & ref & ref & ref \\
\hline \multicolumn{4}{|l|}{ Wealth index } \\
\hline Poorest & $2.3(1.69,3.16) *$ & $1.8(1.02,3.03) *$ & $1.3(0.66,2.64)$ \\
\hline Poorer & $1.5(1.12,3.05) *$ & $1.2(0.69,1.97)$ & $0.8(0.45,1.55)$ \\
\hline Middle & $1.4(1.05,1.89) *$ & $1.3(0.76,2.08)$ & $0.9(0.48,1.59)$ \\
\hline Richer & $1.2(0.86,1.52)$ & $1.2(0.75,1.95)$ & $0.9(0.52,1.56)$ \\
\hline Richest & ref & ref & ref \\
\hline \multicolumn{4}{|l|}{ Health insurance } \\
\hline No & $1.4(1.01,2.06) *$ & $1.7(0.91,3.06)$ & $1.1(0.64,1.71)$ \\
\hline Yes & ref & ref & ref \\
\hline \multicolumn{4}{|l|}{ Child ever born } \\
\hline 1 & ref & ref & ref \\
\hline $2-4$ & $1.1(0.89,1.27)$ & $2.1(1.44,2.83) *$ & $1.3(0.98,1.77)$ \\
\hline $5+$ & $1.1(0.86,1.34)$ & $2.5(1.65,3.74) *$ & $1.1(0.71,1.76)$ \\
\hline \multicolumn{4}{|c|}{ Perceived distance to health facility } \\
\hline Big problem & $1.1(0.97,1.29)$ & $1.5(1.12,1.88) *$ & $1.3(0.97,1.75)$ \\
\hline Not a big problem & ref & ref & ref \\
\hline \multicolumn{4}{|c|}{ Own account in a bank or other institution } \\
\hline Yes & ref & ref & ref \\
\hline No & $1.4(1.23,1.77) *$ & $1.2(0.82,1.85)$ & $1.2(0.87,1.67)$ \\
\hline \multicolumn{4}{|l|}{ Mobile ownership } \\
\hline No & $1.3(1.11,1.64) *$ & $1.6(1.2,2.32) *$ & $1.1(0.77,1.6)$ \\
\hline Yes & ref & ref & ref \\
\hline \multicolumn{4}{|l|}{ Region } \\
\hline Tigray & $1.5(0.85,22.55)$ & $0.6(0.24,1.56)$ & $1.1(0.62,1.78)$ \\
\hline Afar & $6.9(3.83,12.3) *$ & $5.6(2.01,15.9) *$ & $1.4(0.64,3.19)$ \\
\hline Amhara & $4.4(2.56,7.65) *$ & $4.0(1.55,10.2) *$ & $1.3(0.72,2.47)$ \\
\hline Oromia & $7.3(4.25,12.6) *$ & $3.9(1.55,10.2) *$ & $2.6(1.32,5.04) *$ \\
\hline Somali & $12.2(6.93,21.6) *$ & $4.2(1.53,11.6) *$ & $4.9(1.93,12.24) *$ \\
\hline Benishangul & $2.2(1.23,3.81) *$ & $2.4(0.92,6.11)$ & $0.8(0.44,1.56)$ \\
\hline
\end{tabular}




\begin{tabular}{|c|c|c|c|}
\hline SNNPR & $2.9(1.70,4.98) *$ & $2.4(0.96,6.0)$ & $1.8(0.98,3.29)$ \\
\hline Gambela & $4.2(2.38,7.28) *$ & $3.3(1.26,8.54) *$ & $1.3(0.68,2.38)$ \\
\hline Harari & $7.2(4.14,12.6) *$ & $2.3(0.85,6.14)$ & $9.9(4.14,24.0) *$ \\
\hline Dire Dawa & $1.3(0.75,2.39)$ & $1.1(0.43,3.02)$ & $3.0(1.55,5.66) *$ \\
\hline Addis Ababa & ref & ref & ref \\
\hline \multicolumn{4}{|c|}{ Place of residence } \\
\hline Urban & ref & ref & ref \\
\hline Rural & $1.2(0.86,1.67)$ & $3.1(1.75,5.26) *$ & $1.1(0.67,1.96)$ \\
\hline \multicolumn{4}{|c|}{ Community education } \\
\hline Low & $1.1(0.92,1.41)$ & $1.1(0.81,1.59)$ & $0.8(0.51,1.11)$ \\
\hline High & ref & ref & ref \\
\hline \multicolumn{4}{|c|}{ Community poverty status } \\
\hline Low & ref & ref & ref \\
\hline High & $1.3(1.01,1.63) *$ & $1.3(0.87,1.88)$ & $1.1(0.67,1.58)$ \\
\hline \multicolumn{4}{|c|}{ Community media exposure } \\
\hline Low & $1.5(1.23,1.86) *$ & $1.6(1.14,2.23) *$ & $1.3(0.85,1.86)$ \\
\hline High & ref & ref & ref \\
\hline \multicolumn{4}{|l|}{ Random effect } \\
\hline Variance & $0.5(0.36,0.64) *$ & $0.8(0.47,1.21)$ & $0.4(0.22,0.87) *$ \\
\hline ICC (\%) & $12.6 \%$ & $18.8 \%$ & $11.7 \%$ \\
\hline \multicolumn{4}{|l|}{ Model fitness } \\
\hline Log likelihood & -3329 & -1073.6 & -955.9 \\
\hline AIC & 6721.7 & 2213.1 & 1977.9 \\
\hline
\end{tabular}

Models with individual and community variables. Abbreviations: -AOR: Adjusted Odds Ratio: adjusted for selected sociodemographic and economic variables and community factors, ICC: Intra-cluster correlation coefficient, AIC: Akaike information criterion; ref: reference group; Significance level: ${ }^{*} \mathrm{p}<0.05$ 